\title{
Development and the Environment: Some Basic Issues
}

\author{
J.N. Blignaut and E.F. Heymann
}

Given its unique economic and social circumstances, South Africa is in desperate need of economic development. The main impetus for growth will have to come from the mining and industrial sectors, which will have to play a key role in the future South African economy. The activities of these sectors markedly influence the quality and quantity of natural resources in the country. Sustainable development should be the ultimate goal of any development strategy. The question is how businesses should organise themselves to achieve the goal of sustainable development, with cleaner and ecologically more efficient production. This study first analyses the unique features of resource economics in South Africa. It then discusses the integration of sustainable development within an excavatory and production environment. Finally an appropriate business management philosophy will be outlined.

\section{Resource Economics in South Africa}

The importance of resource economics in South Africa is acknowledged by a small but rapidly growing group of academics, nongovernmental organisations, parastatals and state departments. Numerous workshops*(2) were frequently held in an effort to bolster support for the subject, guide research and develop the approach that should be followed in future. Research was to cover, amongst other things, the valuation of bio-diversification, environmental accounting, market-based incentives and direct commandand-control measures, sustainable water management and the sustainable management of wilderness areas. Unfortunately, not much progress has been made so far beyond the point of discussion and research.

The lack of progress is largely due to the fact that the environmental milieu in South Africa is characterised by various unique and even conflicting features. The way in which the features of the environmental milieu are going to be managed determines the success rate of and the course of the future development of resource economics. Six features will be discussed here.

1. The government. In March 1994 the African National Congress (ANC) issued the Reconstruction and Development Programme (RDP) (ANC 1994) as an election manifesto. In November 1994, an RDP White Paper (RSA 1994) was released. Whereas the first election document contained various sections and a chapter on the environment and the sustained use thereof, the White Paper made no reference to the environment or any environmental concerns at all. The White Paper served as a base document for the writing of the economic policy document Growth, Employment and Redistribution: a Macroeconomic Strategy (GEAR) (RSA 1996a). The environment does not feature in GEAR either. Government and the other NEDLAC participants (Business South Africa and Labour) are actively implementing GEAR -without, however, incorporating environmental issues in the day-to-day activities. These documents were written despite the White Paper onEnvironmental Management policy for South Africa (RSA 1997c) and the fact that Section 24 of the Bill of Rights in the Constitution of the Republic of South Africa guarantees environmental rights for all the people of South Africa. *(3)

Although the government has committed itself to environmental equity and sustainable development through the constitution and the election document, economic policy and everyday realities do not reflect the same commitment.

2. Natural environment means different things to different people. First, the industrial sector generally views the environment as an input or even a waste basket. Second, it serves as a source of income and a means of livelihood for farmers and promoters and practitioners of eco-tourism. Third, for the general citizen it is simply a place to live in. The fourth group perceive the environment as an asset to be used with care and with a strong sense of stewardship. Finally, rural peasants view it as the source of life, often with strong religious overtones.

Given these diverse perspectives, it is difficult to find common ground amongst those that have an important role to play as a starting point for negotiations towards developing a comprehensive policy for the environment. For example, a mining company may have acquired the rights to mine a certain area by virtue of its ownership of the mineral rights. Frequently, however, mining companies do not possess freehold title to the surface. The surface rights have to be acquired or leased from the holder of the freehold title. Within a (South) African context the holder can, for example, be a tribal leader. The area concerned could very possibly be sacred ancestral land which the local community collectively use for cattle ranching. Further, the land may lie within a sensitive eco-system which is generally regarded to be unsuitable for cattle farming or mining. In such a situation the conflicting 
and perhaps irreconcilable views of the mining sector, environmentalists and the rural inhabitants, there is little possibility of an amicable solution, irrespective of the economic, or any other, analytical technique used.

The underlying and mutually exclusive views of the various role players act as the second feature which determines the realm within which resource economics must operate.

3. In a country plagued by absolute poverty and numerous other social disorders, it is generally perceived that environmental issues are of secondary importance. An economic growth and development policy through industrialisation is generally perceived to be the best option given the social and economic demands. Environmental concerns are consequently excluded in pursuit of these priorities.

2. Apathy with regard to the current carrying capacity of the environment and quality of life, as well as apathy towards the quality of life of future generations. Apathy with regard to the well-being of future generations may not apply to rural peasants; environmental degradation, however, occurs not because of apathy but because of illiteracy, accompanying lack of knowledge, poverty and other pressing social issues. A feature that permeates from the apathy-syndrome is that of international dumping. In the desperate search for direct foreign investment, investments from companies are accepted without a proper prior environmental impact assessment. This tendency, however, is slowly changing.

5. Information on the use of natural resources is either non-existent or very difficult to obtain. Should an independent researcher or research body have access to information, it is very likely that they may not be permitted to use or publish it. Environmental information is enveloped in numerous regulations that protect companies from disclosing their impact on the environment.*(4) However, this may change in the foreseeable future, as Section 32 of the Constitution states that" everyone has the right of access to any information that is held by another person and that is required for protection of any rights" (RSA 1996b: 14).

National legislation must still be enacted to give effect to this right, but it is clear that companies in future will have to allow access to environmental information under certain conditions.

6. There is a lack of institutional capacity and responsibility. Given the apathy mixed with scepticism against those with environmental concerns as well as the various possible perspectives on the environment as described earlier, institutions are reluctant to invest much time and money in the environment. Within these institutions - business corporations, statutory organisations and government departments - the importance of the environment is recognised and allocated sufficient resources. Although there may be individuals who desire to pursue the goal of sustainable development, resources are not made available for such research.

Given the simultaneous existence of these features, a new approach to environmental economics is essential.

\section{Sustainable Development: The Paradox}

The aim of resource economists in South Africa should be to convince the parties mentioned before that the perceived trade-off and mutual exclusiveness between development on the one hand and the environment on the other, are a fallacy. This perceived trade-off should be diverted to environmentally inclusive sustainable development. Figs. 1 -2 (of which the shapes are hypothetical and not empirically determined) provide the necessary analysis to illustrate the need for and the eventual result of such a change in perspective.

Figure 1. Environmental Concern, Economic Development and Environmental Use

Fig. 1 illustrates that while a country has a subsistence economy, which is generally viewed as agrarian or non-developed (point $a$ ), a relatively high level of environmental concern is present. The level of environmental use on the other hand is relatively low. The reason for this situation is the fact that the country lives close to the environment and there is a strong, even religious, connection to the land and its other resources.

As economic development, conventionally defined, takes root or is enforced, the nation is removed from its roots, the general pattern being that of urbanisation, growth of population and elements of industrialisation. Poverty and many other social disorders, however, still remain. The result is that environmental concerns decline whilst the priority shifts towards higher levels of industrialisation in the pursuit of growth and development in order to survive (Meier 1995:29-30). This decline in the concern for the environment in favour of industrialisation is indicated by the negative sloping part of the concern function. The decline in 
environmental concern in favour of industrial development continues until it reaches a minimum at $b$. After a degree of development has been obtained, environmental concerns once more gain in prominence. This is indicated by the positive sloping part of the concern function. The position of a developed country can for example be depicted by c.

A simultaneous process is that of environmental impact as illustrated by the use function. As the level of industrial development increases, environmental use increases as well. At a high level of development the constant increase in environmental concerns accompanied by the availability of science and technology, leads to the decline in the usage rate of the environment and eventually the level of environmental use will start to decline, as at point $d$. It is important to note that the turning point in the concern function is much earlier than is the case with the use function. This tendency illustrates the fact that both development and environmental concerns are perceived to have to be at high levels before an impact on the level of environmental use is possible. What is clear from the above is the conventional trade-off between environmental concerns and industrialisation for young and developing economies. In order to achieve high levels of industrialisation, environmental concerns and environmental priority are low at point a and where the level of environmental concerns and priority is high, industrialisation is low, indicated at point $b$.

Whereas Fig. 1 illustrates the present situation, Fig. 2 illustrates the challenge resource economists, companies and a country in general are facing. The perceived strong positive relationship between the level of industrialisation and the level of environmental use must be conceptualised as one or other kind of negative sloping function.

Fig. 2 duplicate the use function of Fig. 1, but is labelled Old Use. Likewise is the concern function duplicated, but with the understanding that the initial decline in environmental concern as the level of industrialisation increases is lower than the current position as portrayed in Fig. 1. The third function in Fig. 2 is labelled New Use. The New Use function indicates, as the Old Use function, an initial positive relationship between environmental use as the level of industrialisation increases (the phase of structural adjustment from an agrarian society to one of industrialisation). New Use, however, reaches its maximum point much earlier and at a much lower level than environmental use than the Old Use function. The reason being the incorporation of environmental concerns in the decision making process, whereupon the desired negative relationship.

Given a level of industrialisation, presented by $a$, the aim is to move from $d$ where the environmental use is high (indicated byj), to a point $b$, which represents the same high level of industrialisation (a) but with the full incorporation of environmental concerns (c). Consequently, environmental use is much reduced, as represented by e.

Before examining how companies, in particular, can go about applying environmentally sustainable principles themselves, the foundation of the argument presented in Fig. 2 will be evaluated against known sustainable development theory.

Figure 2. Sustainable Development: Incorporating Environmental Aspects in Development

\section{Sustainable Development: The Theory}

Sustainable development remains a nebulous concept, although it has been shaping political and economic agendas since the release of the Brundtland Report (the proceedings of the World Commission on Environment and Development conference held in 1987 under the auspices of, amongst others, the United Nations). The Brundtland definition of sustainable development is still the most pervasive and entails that sustainable development is development that meets the needs of the present without compromising the ability of future generations to meet their own needs (WCED 1987).

With natural resources being often a relatively scarce production factor, sustainable development is very much part of the business (or economic) domain. Unfortunately it is almost exclusively restricted to political rhetoric and is not yet playing its proper role in everyday business and economics.

Analyses of sustainable development (Stone 1994) and of environmental sustainability (Goodland 1995) are discussed further below in an effort to extend the analysis discussed around Fig. 2 above.

Sustainable development implies different things to different people, but the two key interpretations of sustainable development are those of eco-efficiency and eco-justice. Stone (1994:5) describes eco-efficiency as being main-stream (growth-orientated) economic thought, western capitalism and free market economic systems, but amended to include environmental issues.

Opportunity, creativity and management skills are challenged, but not basic assumptions, values, lifestyles or prevailing modes of business activities. According to Stone eco-efficiency may be seen in concerns and efforts of business in conservation, waste 
minimisation and the prevention of pollution, recycling, technological improvements (e.g. leading to cleaner production) and environmental protection (e.g. end-of-pipe solutions - treatment of pollution and the depletion of resources after they had occurred).

Eco-efficiency is thus primarily concerned, in a business sense, with maintaining the status quo, but with the maintenance of, 01 increase in, output value combined with reduced inputs of production factors (e.g. environmentally friendly automation). Eco-efficiency on its own in essence remains a trade-off concept. In Fig. 2 eco-efficiency is located at point g which is the equilibrium point between the levels of industrialisation, environmental use and environmental concern.

Second, eco-justice challenges basic mainstream (growth-oriented) economic thought and the free market economic systems. Basic assumptions, values, lifestyles and prevailing modes of business are questioned. Eco-justice questions the very fundamentals of economic theory and activity and reiterates the three basic economic questions namely what, how, and for whom to produce. It may thus demand a reduction or even an elimination of certain goods and services. Eco-justice challenges the notion of economic growth as the dominant driving force and measure of economic health since economic growth is perceived to be too narrow a performance indicator. Eco-justice is far more life- and environment-centred and is in this sense not business-centred. Eco-justice on its own is an untenable concept, which is located at /' in Fig. 2 (low environmental use - high preservation - and low levels of industrialisation).

Should sustainable development as philosophy be accepted, it could be concluded that sustainable development is not achievable within the domain of eco-efficiency alone, but that eco-justice is a necessary adjunct. Point $e$ in Fig. 2 indicates the approximate environmentally sustainable development goal. It should be clear that for any business to meet the requirements of sustainable development, an environmental conscience is needed which goes beyond that of eco-efficiency and compliance with legislation. In an analysis which parallels that of Stone to some extent, Goodland (1995:15) describes three degrees of environmental sustainability, namely weak, strong and absurdly strong sustainability:

1. Absurdly strong environmental sustainability places the earth and all its inert substances as well as living species on the same level. In essence it means that no natural resource should ever be depleted. When applied (for instance) to the exploitation of a non-renewable resource such as oil and minerals, it means that such exploitation may not take place at all. Absurdly strong environmental sustainability could be linked to the views held by the so-called deep ecologists. Gray et al. (1996:60) describe deep ecologists as those who believe that human beings do not have any greater rights to existence than any other form of life (see point $i)$.

3. Strong environmental sustainability allows for the exploitation of resources (even non-renewable), but stresses that the receipts (or income) from such exploitation must be specifically invested in research or other activities which eventually will (or should) ensure that alternative renewable resources will be available for future generations. These views could be said to overlap to some extent with those held by social ecologists. Gray et al. (1996:58) describe social ecologists as those who are concerned for the environment in the sense that they see serious problems developing if nothing is done about environment-organisation interactions. They also consider that organisations have been influential in creating the social and environmental problems and should as a matter of retribution be instrumental in helping to eradicate the problems. The analysis of Goodland parallels the ecoefficiency and eco-justice concepts described by Stone. Strong environmental sustainability thus lies at point $e$ in Fig. 2. 3. Weak environmental sustainability allows for the exploitation of all resources, provided that it is done eco-efficiently. The receipts or profits of such exploitation should ideally be applied generally to the benefit of mankind. This view is in line with those who consider themselves to be expedient capitalists (Gray et al. 1996:58). This view considers that long-term economic welfare and stability can only be achieved if wider social and environmental responsibilities are accepted. The view corresponds with point $g$ in Fig. 2. It should be clear that weak environmental sustainability and the eco-efficiency concept of sustainable development have much in common, whilst strong environmental sustainability moves into the domain of both eco-efficiency and eco-justice. The proponents of conventional mainstream (growth-oriented) economic democracy will have no interest in any form of environmental sustainability. For them the ethic of utilitarianism is the key to human development. This utility is currently measured in organisations in terms of the generation of short-term profits for shareholders. In such a framework where price is the epi-centre of theory and practice, there can be no concern for either social or environmental issues. There is therefore no extremely weak category of sustainable development. Even though not a 'category', this point is indicated as $d$ in Fig. 2. 
Fig. 2 adequately represents the theory on which sustainable development and environmental sustainability are based. How, in practice, should government and business move from the position as depicted in Fig. 1 to a situation as depicted by $e$ in Fig. 2, while the eventual result of environmentally sustainable development remains in question? Macroeconomic policy (for government) and business philosophy (for companies) should indicate which of the above-mentioned concepts of sustainable development should be pursued. If government policies or business philosophies are based exclusively on growth-orientated economic principles, they will have no appetite for real change and it will become all the more difficult to uphold the environmental image. Should government policies and business philosophies require environmentally sustainable development (as is required in the S.A. Constitution), effective implementation is required.

No conventional policy measures, whether command-and-control (because of differences in philosophy, lack of policing and enforcing capacity, etc.) or incentive-based incentives (because of the lack of sophistication, properly rights demarcation, measurement and education, etc.), will succeed in motivating all the relevant parties to subscribe to the notion of environmentally sustainable development. It will be in the self-interest of all parties to apply environmentally sustainable development principles by themselves. The subsequent discussion focuses primarily on what business should (or could) do to move from the situation depicted in Fig. 1 to a situation represented by e in Fig. 2.

\section{A New Management Approach Required}

As argued above, no external force will be able to promote effectively the increase in the concern for the environment. This is also true for business in this country. South African business enterprises should not only focus on voluntary initiatives such as internal management systems; these by themselves will not contribute fully to an environmentally sustainable development solution. The solution lies in the creation of an environmental ethic through a change in outlook in management philosophy. A new environmental ethic is required in companies over and above the conventional voluntary initiatives, command-and-control and any other environmental policies. This change in business philosophy is fundamental for sustainable development to succeed and the change should go beyond the mere presence of an environmental image.

By creating an environmental desk or section that is responsible for environment-related aspects, the responsibility of others in the organisation (e.g. the Chief Executive Officer, board of directors, production, engineering, accounting, purchasing, quality, etc.), generally does not change. It is presupposed that the environmental duties of the companies are fulfilled by the environmental department. The status quo is therefore maintained within departments like producing and selling, with consequently no or little need to integrate environmental concerns into their planning, decision-making and operations.

The person responsible for environmental management within the firm or plant is usually a senior manager with a technical or operations background. Very seldom are directors, marketing managers and accountants involved in environmental management. Their involvement is usually restricted to commentary on the environmental manager's budget so far as it concerns environmental problems. The environmental department is therefore seen as a cost item and not as an integral part of value-adding to the business.

Notwithstanding the fact the institutional capacity of the government to police regulations have been (and still is) abysmal, compliance with environmental legislation more often than not directs the activities of the department of the environment. Given the limitations of the government's policing capacity, internal pressure on the environmental manager to ignore transgressions increases. In the few instances where prosecution has lead to conviction the fines are often paid by companies without delay, as the abatement cost is often much higher than the fine. This clearly illustrates that command-and-control policies have neither worked in the past, nor will they work in future, as the lack of institutional capacity is bound to continue.

Many concurrent environmental policy processes have been launched by the S.A. government over the past few years in order to consider shortcomings in environmental legislation and institutional capacity. These include the Consultative Process for An Environmental Policy for South Africa (RSA 1996c), the Draft Environmental Impact Regulations (RSA 1996d), the Minerals Policy Process (RSA 1996e), the Water Law Review (RSA 1997a), and the Integrated Pollution Control and Waste Minimisation Project (RSA 1997b). All these initiatives will eventually lead to White Papers and, perhaps, legislation. However, without the resources to implement and police these initiatives, it may be assumed that the conduct of business will not change, regulations will largely be ignored, and companies will remain in the vicinity of point $d$ or at the utmost at point $g$ in Fig. 2. The status quo is therefore untenable and the management philosophy will have to change. Businesses will have to be educated and convinced that it is in their own best interest to accept a business philosophy that is environmentally sound. 
In the quest for cleaner production and environmentally sustainable development, companies must as an absolute minimurr requirement comply with environmental legislation (despite the inability of institutional capacity to enforce regulations). They should also change their entire outlook and so ensure that the company makes a contribution to environmentally sustainable development. This could only be done if an environmental ethic is introduced which entirely changes management philosophy. The rationale behind the incorporation of an environmental ethic within management philosophy, will be the embodiment of the public opinion (or public choice) within the business sphere. Should an environmental ethic be internalised, environmental concerns will be internalised without external force or coercion and this will support environmental sustainable development, the ultimate goal.

\section{Business and the Environment}

The emphasis of sustainable development, irrespective of the degree thereof, will be the maximisation of profits, the development of people and the sustainable use of the environment (the Profit-People-Environment-principle) simultaneously (compare Fig. 2). It needs the conscious effort from an organisation to embark on such an exercise. A company can make no contribution to sustainable development if it does not seriously examine its raison d'etre in the light of environmental issues.

\section{(a) Vision}

The vision of a company may include aspects like the desire to be the biggest, the best, a world leader, industrial leader, expert follower, or to have high real growth, above average return on assets, excellence, etc. The contribution of the company to environmentally sustainable development is seldom (if at all) part of the overall vision of a company. If it is not part of the vision it will not be carried forward into any strategy, goals, objectives and targets which the company may set itself. There can in such instances be no real progress toward the quest for environmentally sustainable development.

When a company adopts an environmentally sustainable development policy, it should ensure that the full implications of such an action is fully understood by all concerned. The status quo within normal business activities cannot be maintained if sustainable development underlies the business philosophy. Companies cannot adopt environmentally sustainable development as a guiding principle, but fail to understand the full consequences of such an action. Should a company envision to subscribe to sustainable development, the implementation of such a vision should be addressed by the company itself.

\section{(b) Environmental Management, Information Systems and (cleaner) Production}

Visions in themselves, although a necessary prerequisite, are not enough and do not guarantee action. Action is necessary to ensure environmentally sustainable development, also called the area of narrow environmental management. Environmental management is not a concept foreign to business. Many management tools have been developed to help business implement the environmentally sustainable vision. Such a management system should apprehend any possible conflict that may arise among various departments within the firm.

Interest groups (and shareholders especially) should in turn take cognisance of the scope of the vision. The implementation of the vision could have a negative effect on the short to medium term profitability of the company. In turn, it is the responsibility of the company to educate its interest groups so that the benefits of adopting a sustainable development will be evident over the longer term. This includes the integration of environmental management with all management functions to ensure that the longer term goals are met. Environmental management systems and environmental data and information must therefore be fully integrated with company-wide management functions as well as company information systems and not be seen as just another departmental function.

Full integration of environmental management with all aspects of the company management (from strategic planning through to shop floor operations) is bound, over a period of time, to move a company (and hence a country) from $d$ to $e$ in Fig. 2. Dividends from ascribing to the Profit-People-Environment-principle should be evident in the monetary results as well as in relations and trust amongst all interest groups and the company. Other factors such as the reduction of pollution, the use of resources and the reduction of the impact are logical results of the integration of management systems. Cleaner production should thus be a natural outcome for a company, if the fundamentals are firmly in place and cemented into a generally accepted policy.

(c) Environmental Accounting

The integration of environmental management with all aspects of company management will contribute towards the realisation of 
environmentally sustainable development. However, the actual contribution made towards sustainable development will pass unnoticed if the successes (and failures) are not properly recorded and disclosed.

Should companies wish to demonstrate their contribution to and participate in environmentally sustainable development, they will have to bridge the world of environmental management with that of finance and economics. This is where the accounting department interacts with the department of the environment. This interaction introduces the concept of environmental accounting. Environmental accounting focuses on the monetary implications of the environmental impact and aspects of an organisation, including implications for cash outlays and revenues, etc. It translates environmental impact and concerns into monetary values. Environmental accounting is therefore very different from environmental indicator reports inasmuch as environmental indicator reporting focuses on physical quantities in natural units.

The two main categories of environmental accounting are those of accounting for the environment and accounting for sustainability. Apparently most companies in South Africa have not yet given much thought to either one of these. Some have considered eco-efficiency accounting, which in reality is accounting for the environment. Such accounting does not challenge basic business assumptions, values or life styles. The status quo of business operations is therefore still upheld.

Accounting for sustainability goes much deeper. It also incorporates the equity paradigm of eco-justice. This firmly introduces the previously discussed triple minimum requirement of Profit-People-Environment into the accounting function. In order to contribute to environmentally sustainable development a company will have to satisfy all three these conditions.

The incorporation of Profit-People-Environment into accounting introduces environmental externalities into an incentive-based economic model. The debate on whether or not - and how - to value the environment is ongoing and has as many protagonists as detractors. Some argue that you can never accurately put a price on nature and that all attempts to bring nature into the neo-classical economic model will fail. Others are convinced that if you do not attempt to find some way in which to value nature (even if the valuation is not necessarily absolutely correct) the process of environmental degradation continues.

When a company appreciates the importance of sustainable development, it should devise an equitable means of valuing its use oi the environment, irrespective of whether it relates to the degradation or to the depletion of resources. It is essential that this valuation be disclosed in the company accounts.

The thoroughness and success of environmental accounting will be determined by the vision and philosophy of the company. Companies with a well-defined vision of sustainable development will want to embark on full-cost environmental accounting. This implies that the accounting will incorporate both private (company) and societal environmental costs.

Those companies without an environmentally sustainable development vision may only prefer to use private environmental accounting, for instance, to bring into consideration environmental technology, compliance and management systems.

Some guidelines have been published which could assist companies to come to a decision about environmental accounting. These incladedEnvironmental Issues in Financial Reporting (Anon 1995a) issued by the Accounting Advisory Forum, the Accounting and Reporting Practices in the Mining Industry (Anon. 1995b), and the Stakeholder Communication in the Annual Report (Anon. 1997), the latter two both issued by the South African Institute for Chartered Accountants. These booklets focus on eco-efficiency accounting and not on accounting for sustainability or eco-justice.

(d) Conceptual Model for a New Management Approach

If a company is serious about contributing to environmentally sustainable development, a fundamental internal paradigm shift is required. External forces such as command-and-control and resource economics will underpin efforts to contribute to environmentally sustainable development, but cannot provide the continued impetus over a sustained period. This can only come from within the company.

By accepting the responsibility of environmental stewardship and the principles of sustainable development as prerequisites for sustained business activities and to act in its own interest, a company will have to transform its whole management system.

\section{Conclusion}

Resource (sic) environmental economics has come a long way in South Africa during the 1990s. The efforts include appropriate capacity building, the development of an environmental awareness (sensitivity) and the writing of an environmentally friendly constitutional framework. Notwithstanding, much still needs to be done. With regard to environmentally sustainable development, one of the main challenges South Africa faces is the integration of environmental concerns and the need for economic development through economic growth. This challenge implies the sustainable use of environmental 
resources whilst generating economic growth. The implementation of this challenge requires a change in the management approach towards the use of the environment. It implies that business must accept their environmental responsibility and demonstrate it by a change in all corporate operations.

\section{References}

ANC (AFRICAN NATIONAL CONGRESS). 1994. The Reconstruction and Development Programme. Johannesburg: Umanyano Publications.

ANON. 1997. Stakeholder Communication in the Annual Report. Corporate Governance Series. Kengray: The South African Institute of Chartered Accountants.

ANON. 1995a. Environmental Issues in Financial Reporting. Document of the Accounting Advisory Forum, Doc. XV/6004/94 cl rev4.

ANON. 1995b. Accounting and Reporting Practises in the Mining Industry. Corporate Governance Series. Kengray: The South African Institute of Chartered Accountants.

GOODLAND, R. 1995. The Concept of Environmental Sustainability. An unrevised proof document from Annual Reviews.

Washington: World Bank, Environment Department.

GRAY, R., OWEN, D. \& ADAMS, C. 1996. Accounting and Accountability: Changes and Challenges in Corporate Social and Environmental Reporting. Europe: Prentice Hall.

MEIER, G.M. 1995. Leading Issues in Economic Development. Oxford: Oxford University Press.

RSA. 1994. White Paper on Reconstruction and Development. Cape Town: Government Printers.

(15 November)

RSA. 1996a. Growth, Employment and Redistribution: a Macroeconomic Strategy. Pretoria: Department of Finance.

RSA. 1996b. Constitution of the Republic of South Africa. Act no 108 of 1996. Government Gazette 378(17678), 18 December: $10-11$ \&14.

RSA. 1996c. An EnvironmentalPolicy forSouth Africa. Green Paper for discussion. Pretoria: Department of Environmental Affairs and Tourism.

RSA. 1996d. Proposed regulations under Section 26 of the Environmental Conservation Act, Act no 73 of 1989. Government

Gazette 377(17517), notice no 1752, 1 November:7- 8.

RSA. 1996e. Mining and Minerals Policy: Revised Discussion Document. Minerals Policy Process Steering Committee. Pretoria: Department of Minerals and Energy: Secretariat. (7 June)

RSA. 1997a. White Paper on a NationalWaterPolicy forSouth Africa. Pretoria: Department of Water Affairs. (April)

RSA. 1997b. Discussion Document towards a White Paper on Integrated Pollution Control and Waste Management. Draft 5.

Pretoria: Department of Environmental Affairs and Tourism. (22 May)

RSA. 1997c. White Paper on Environmental Management in South Africa. Notice 1096 of 1997. Government Gazette 385 (18164), 28 July: 30-32.

Stone, D. 1994. No longer at the end of pipe, but still a long way from sustainability: A look at management accounting for the environment and sustainable development in the United States. Centre for Social and Environmental Accounting Research. Dundee Discussion Papers in Accounting and Business Finance (ACC/9408). Dundee: Department oi Accountancy and Business Finance, University of Dundee. WCED (World Commission on Environment and Development). 1987. Our Common Future (Brundtland Commission Report). New York: Oxford University Press. 


\section{Endnotes}

\section{1 (Popup - Popup)}

Senior Lecturer, Department of Economics, University of Pretoria, and Group Environmental Consultant for Anglo American Platinum Corporation, the Views Expressed Reflect Those of the Authors and not Necessarily Those of Any Institution They May Be Involved With, the Authors are Also Indebted to Professors D.j.j. Botha and P.a. Black for Invaluable Comments and Editorial Assistance. We Accept Full Responsibility for the Contents of the Article.

\section{2 (Popup - Popup)}

Two in 1992 and in 1993 (Department of Environmental Affairs and Tourism); two workshops in 1994 (Development Bank oi Southern Africa); two during 1996 (Council for Scientific and Industrial Research and the South African Reserve Bank respectively). During 1997 and 1998 a number of meetings were held which include a seminar series, hosted by the Development Bank of Southern Africa, under the auspices of the National Advisory Committee on Sustainable Development in South Africa.

\section{3 (Popup - Popup)}

Everyone has the right:

a. to an environment that is not harmful to their health or well-being; and

b. to have the environment protected for the benefit of present and future generations,

i. through reasonable legislative and other measures that prevent pollution and ecological degradation;

ii. promote conservation; and

iii. secure ecologically sustainable development and use of natural resources while promoting justifiable economic and social development (RSA 1996b: 10-11).

4 (Popup - Popup)

The pressure for disclosing information on the economic impact on the environment is current mounting. The Development Bank of Southern Africa has compiled the first comprehensive environmental database for South Africa for the financial year 1992/93. It has, however, not been officially released. 